ISSN: 0213-2052 - eISSN: 2530-4100

DOI: https://doi.org/10.14201/shha202139403423

\title{
LA BIOGRAFÍA CRISTIANA ENTRE REALIDAD Y RETÓRICA: EL CASO DE GAUDENCIO DE BRESCIA
}

\section{Christian Biography between Reality and Rhetoric: the Case of Gaudentius of Brescia}

\author{
Carla SETIÉN GARCÍA \\ Universidad de Cantabria \\ carla.setien@unican.es
}

Fecha de recepción: 19-3-2021 Fecha de aceptación: 26-05-2021

ORCID: https://orcid.org/0000-0002-4664-3568

RESUMEN: La biografía cristiana de los primeros siglos se caracterizaba principalmente por presentar los aspectos que hacían del biografiado un hombre santo, lo cual conllevaba, ineludiblemente, exageraciones y relatos artificiosos. En este trabajo se examina una de las primeras biografías, si no la primera, del norte de Italia. Fue escrita por Gaudencio de Brescia en el primer decenio del siglo V para conmemorar a Filastrio, predecesor suyo en la sede episcopal. Un detallado análisis histórico-filológico de este escrito junto con el de la obra del propio Filastrio y otras fuentes de la época nos permiten averiguar la historicidad de los orígenes y circunstancias vitales de este. Entre estas destacan su predicación ambulante por amplios territorios, la lucha contra el arrianismo en la ciudad de Milán y, finalmente, su labor en la constitución definitiva de la primitiva comunidad cristiana en Brescia.

Palabras clave: género biográfico; siglo IV; Gaudencio y Filastrio de Brescia; norte de Italia. 
ABSTRACT: The Christian biography from its first centuries was primarily characterized by presenting the aspects that made its subject a holy man, which inescapably led to exaggerations and contrived accounts. This paper examines one of the first, if not the first, biographies from Northern Italy. It was written in the first decade of the 5th century by Gaudentius of Brescia to celebrate Filastrius, his predecessor in the episcopal seat. A detailed historical-philological analysis of this writing together with that of the work of Filastrius and other sources from the same period allow us to find out the historicity of his origins and biographical circumstances: his traveling preaching across broad territories, the fight against Arianism in the city of Milan and, finally, his undertaking in the definitive constitution of the Christian community in Brescia.

Keywords: biographical genre; 4th century; Gaudentius and Filastrius of Brescia; Northern Italy.

\section{INTRODUCCIÓN}

En los primeros años del siglo V Gaudencio, siendo obispo de Brescia, en el norte de Italia, pronunció una breve, pero emotiva, laudatio funebris en honor del difunto Filastrio, predecesor suyo en la sede episcopal de esta ciudad ${ }^{1}$. Según nos cuenta Gaudencio en uno de sus Sermo$n^{2} s^{2}$, Ambrosio fue el promotor de su elección al cargo ${ }^{3}$. De esta forma, el momento de la sucesión episcopal no debió de ser posterior al 397 , año en el que muere el conocido obispo milanés. Según la investigación

1. Cfr. s. v. "Gaudentius 3", Pietri y Pietri 1999, 887-890; "Gaudentius", en Gritti 2018, 251-258. Gritti sitúa el episcopado de Filastrio entre los años 379-387 (135) y el de Gaudencio «ca. 390-410» (251), no sabemos por qué razones. No obstante, asegura que: «La morte di Philastrius e la conseguente consacrazione a vescovo di G. avvene in un anno non precisabile per la documentazione a disposizione, comunque certamente compreso tra il 387, quando Philastrius incontrò Augustinus, [...], e prima del 397, anno della scomparsa di Ambrosius» (ibid., 253). Por lo tanto, el año 387 sería terminus post quem basándose en el testimonio de Agustín, sin embargo, el año 379 no se explica en este fragmento.

2. Los escritos de Gaudencio se encuentran editados en la PL 20, 827-1002 y Glueck 1936 (CSEL 68). Hay dos traducciones modernas en lengua italiana: Banterle 1991; y Truzzi 1996. En el 2017 apareció por vez primera su obra traducida al español por Ramos-Lisón.

3. Gaudent., Serm. 16 (CSEL 68, 139). Según Lizzi 1990, 159, la relación entre Gaudencio y Ambrosio parece que fue muy buena, aunque breve. Este último le invitó a Milán a pronunciar un sermón (Serm. 20) en sus primeros momentos como obispo. Es significativo este detalle, pues no parece que se diera la misma relación entre Ambrosio y Filastrio, ya que no queda ningún testimonio en sus escritos. Para la elección de Gaudencio como obispo y su posterior desempeño en el cargo, vid. Lizzi 1989, 97-137. 
moderna, esta se produjo entre el 396-3974. Con lo que situaríamos el final de Filastrio en torno a estos mismos años.

Filastrio y Gaudencio figuran como los obispos más conocidos de la Iglesia de Brescia desde época antigua hasta el Renacimiento5. Conocemos algunas pinceladas de sus circunstancias vitales gracias a los Sermones (uel Tractatus) que fue pronunciando Gaudencio a lo largo de su mandato como obispo ${ }^{6}$. El último, el número 21, lleva por título Sermo beati Gaudentii de vita et obitu beati Filastrii episcopi, praedecessoris sui y es, con mucho, el documento que mayor cantidad de información nos aporta sobre la persona y vida de Filastrio ${ }^{7}$. Se trata de un panegírico en honor a la vida y obra ejemplar de devoción cristiana de su predecesor $^{8}$. Fue pronunciado ante el pueblo de Brescia con motivo de la décimo cuarta conmemoración de la muerte de Filastrio el día 18 de julio?. Si habían pasado catorce años desde entonces, podemos situar la fecha en la que pronunció este sermón hacia el año 410. Gaudencio aprovecha la ocasión para elaborar, aunque de manera bastante concisa, un típico ejemplo de biografía cristiana ${ }^{10}$. Esta práctica literaria de conmemoración hagiográfica había comenzado ya en el occidente cristiano en el siglo III, pero será a partir de la segunda mitad del siglo IV cuando se desarrolle de manera más profusa ${ }^{11}$. Este tipo de escritos resultan de gran utilidad para

4. Lizzi 1990, 159.

5. Cfr. DHGE, t. 10 (1938), cols. 549-555.

6. De acuerdo con Lizzi 1989, 112, Gaudencio buscaba un término más apropiado para la exposición exegética de la Biblia, pues el uso de sermo pone el acento en el carácter pastoral. En nuestro texto hemos optado por el empleo generalizado de Sermo (Serm.), debido simplemente a una cuestión práctica, pues así lo presenta también el Thesaurus Linguae Latinae (TLL).

7. Wittig 1909, 5, recoge la propuesta de otros dos estudiosos (Januel y Knappe) en la que sugerían que esta laudatio debería llevar por título: "De meritis et virtutibus beati Filastri episcopin, haciendo clara alusión a la temática del escrito.

8. Gaudent., Serm. 21 (CSEL 68, 184-89). Gaudencio se presenta como su sucesor en dos ocasiones: Serm. 16.8 y aquí (21.10). Según Picard 1988, 680, este discurso conmemorativo sería el más antiguo realizado sobre una figura eclesiástica en el norte de Italia.

9. Gaudent., Serm. 21.14 (CSEL 68, 188). El calendario de santos sigue celebrando su santidad este día.

10. Zani 1992, 150, ha señalado el gran parecido que presenta el sermo fúnebre que Gregorio de Nacianzo dedicó a su padre (Oratio 18, PG 35, cols. 985-1044) con la presente laudatio de Gaudencio. Sin embargo, tras una rápida lectura no hemos encontrado parecidos.

11. Deferrari 2001, 7, asegura que para que un texto pueda considerarse hagiográfico debe, en primer lugar, tener un "carácter religioso" y como objetivo principal la "edificación" de la persona elogiada. Según este, "the term in its general sense refers to every written document inspired by and destined to promote the veneration of the saints». El primer ejemplo en occidente es la Vida de Cipriano compuesta por Poncio (ca. 260). Estudios 
conocer y definir las características y funciones de la figura del obispo en este periodo, aunque debemos tener cierta cautela ${ }^{12}$. Es preciso recordar que uno de los objetivos principales de la biografía era el de ofrecer un ejemplo ideal de vida a imitar o admirar, por lo que normalmente se tiende a la exageración tanto de las hazañas del biografiado como de sus cualidades. De ahí que el objetivo primordial del presente estudio es el de examinar y tratar de comprobar, mediante un exhaustivo análisis de las fuentes, el grado de historicidad de este tipo de literatura.

\section{ORIGO}

En la composición de esta laudatio Gaudencio recurre a las características más típicas del género y presenta la vida del protagonista (santificado) a través de la mezcla del relato histórico con el panegírico. Así pues, comienza el exordio expresando su mayor estima para con Filastrio, a quien considera como un padre: honorem debitum beato patri nostro Filastrio [...] deferimus (Serm. 21.1) ${ }^{13}$. A la manera de la retórica clásica, además de la exposición del tema en la parte inicial, el afectuoso apelativo carissimi que, siendo una típica fórmula de cortesía, sirve para captar la atención del público, suscitando las emociones de este al pretender que el santo se encuentra presente entre el auditorio (tamquam vere viventi). En esta primera parte de su discurso compara la vida de Filastrio con la de algunos personajes bíblicos más conocidos. Para ello, recurre a la utilización constante de citas bíblicas, comparaciones y metáforas de lo más útiles para su propósito: ensalzar la figura de Filastrio como el patrono de la ciudad. Entre los recursos empleados por este comentamos a continuación los más significativos. En primer lugar, no solamente concede a Filastrio, de forma simbólica, el máximo honor de ser hijo de Abrahán, sino que incluso lo presenta como un elegido de Dios, a la manera de los doce apóstoles, para que predicara la resurrección futura ${ }^{14}$. Al mencionar la muerte del cuerpo y la prometida resurrección, Gaudencio parece visualizar en el mismo momento la tumba del difunto o, al menos, situarla en un emplazamiento visitable para todos. Según Picard, Filastrio pudo

de referencia sobre el género de la biografía cristiana son los de Cox Miller 1983 y Hägg, Rousseau y Høgel 2000.

12. Marcos 2016 analiza los ámbitos de actuación y carácter del obispo, plasmados en los múltiples textos de biografía cristiana durante los siglos IV-V.

13. En varias ocasiones más Gaudencio se presenta como su discípulo, incluso como su hijo; praef. 4; 16. 8; 21.1; 21.10.

14. Gaudent., Serm. 21.2 (CSEL 68, 185). 
haber sido el primer obispo de Italia del Norte enterrado entre las reliquias de los apóstoles, llegadas a Milán como muy tarde en el $386^{15}$. Cuatro siglos después, el obispo Rampertus cuenta cómo trasladó él mismo en el año $838^{16}$ el cuerpo de Filastrio desde un lugar «venerable», que será identificado posteriormente con la iglesia de San Andrea extra muros, a la catedral de Santa María ${ }^{17}$. Más tarde le fue dedicada una cripta ( «la cripta de San Filastriom), en la que fue definitivamente enterrado ${ }^{18}$.

De esta primera parte del discurso (21.1-4), dedicada al carácter sagrado del obispo, por su relación directa con los más sacrosantos protagonistas de tiempos pasados, y a sus orígenes, Gaudencio pasa a relatar las hazañas que hicieron de este un ejemplo perfecto de "Christi discipulus» (Serm. 21.7). Comienza con una parte narrativa (21.5-10) en la que, siguiendo un orden aparentemente cronológico, describe un acto especialmente relevante en la vida del difunto: el éxodo de su patria (exiit et ipse de terra sua, et de cognatione sua, et de domo patris sui) (21.5). Encontramos esta misma construcción en Gn 12.1 (Vulg.): Dixit autem Dominus ad Abram: Egredere de terra tua, et de cognatione tua, et de domo patris tui, et veni in terram quam monstrabo $t i b i^{19}$. Lo cual nos induce a preguntarnos: ¿hasta qué punto el uso de la Biblia por parte de Gaudencio se puede corresponder con la realidad de Filastrio? Probablemente sea cierto que este decidió dejar su familia — pagana tal vez, o quizás humilde y de ahí el silencio de ambos al respecto- ${ }^{20}$ y su lugar de origen para emprender una vida ascética (ab omnibus saeculi impedimentis exutus) ${ }^{21}$, práctica

15. Picard 1988, 274-275. Podría haber sido en una basílica en donde se encontraban las reliquias de san Andrés, pues ya existía en tiempos de Gaudencio.

16. Marx 1898, 8.

17. Picard 1988, 226-227. Para el culto que recibe a partir del siglo IX, en especial, por parte de Rampertus, cfr. ibid., 433-440, 590-592.

18. Cfr. DACL, vol. 2 1910, cols. 1145-1146. Esta cripta, accesible hoy en día, se encuentra situada a bastante profundidad bajo la basílica paleocristiana de Santa María Maggiore de Dom, construida entre los siglos V-VI. Sobre las ruinas de esta se alzó una iglesia en época medieval, ca. año 1000, dedicada a santa Maria Assunta. Se desconoce en qué fecha pudo haber sido construida. En la cripta en honor a san Filastrio se puede observar la reutilización de elementos de arquitectura romana clásica (columnas, capiteles, etc.), aunque, se ha apuntado, esta refleja una etapa de plena decadencia romana. Tras varios traslados en los siglos posteriores (XV-XVI) sus restos fueron finalmente depositados en la nueva catedral bresciana el 3 de junio del año 1674, cfr. DHGE, vol. 16, cols. 1473-1474.

19. Ed. latina de Tvveedale 2005 (disponible online).

20. Filastrio compuso un catálogo contra las herejías, finalizado probablemente en la última década del siglo IV. Seguimos la edición del texto de Heylen 1957.

21. Gaudent., Serm. 21.5 (CSEL 68, 186). 
que conoció una enorme popularidad en el cristianismo del siglo IV ${ }^{22}$. El que solamente se mencione aquí la emigración de nuestro obispo frente a la total ausencia de información al respecto en otros escritos de la época o en su propia obra, ha llevado a los estudiosos a emitir diversas conclusiones sobre su procedencia. Es el caso de F. Marx, quien lo hacía oriundo de Alejandría o, al menos, de Egipto, aludiendo, entre otros argumentos, a lo inusual que resulta su nombre. Incluso resalta la escritura de este mismo nombre en unas inscripciones funerarias aparecidas en Tebas ${ }^{23}$. Por su parte, Juret, investigador francés de comienzos del siglo XX, basándose en el lenguaje de la obra ${ }^{24}$, asegura no detectar ningún rasgo extranjerizante y, por lo tanto, concluye rotundamente que nos encontramos ante un escritor itálico ${ }^{25}$. Además, incluso apunta ciertos elementos de «orgueil patriotique» que Filastrio dejaría entrever. Juret (1904) afirma que en modo alguno puede ser griego. Para ello se remite a pasajes en los que Filastrio considera a los helenos extranjeros por no existir similitud alguna con los romanos, resultándole así antipáticos. Sin embargo, no deberíamos considerar este un argumento válido, pues muchos son los autores cristianos, de origen griego, que critican duramente la cultura y religión helena, identificándolas con el paganismo con fines puramente retóricos. Entre los más destacados podemos pensar en los primeros apologetas del siglo II como Arístides, Taciano o Justino mártir hasta llegar al siglo IV con Atanasio de Alejandría ${ }^{26}$. Otro especialista más reciente en la obra de Filastrio, concretamente en su uso del texto bíblico, es de la opinión de que no

22. Antonio, Pacomio y Macario (ca. 300-390) son los pioneros del movimiento ascético, llamados "padres del desierto». Estos llevarán a cabo una labor fundamental en la fundación de monasterios por todo Egipto. Cfr. Marcos 2003, 649: «En la segunda mitad del siglo IV los anacoretas se contaban por miles en Egipto». Entre los personajes cristianos más conocidos de Occidente que se adhirieron a este modo de vida se encuentran Jerónimo y Rufino de Aquilea, quienes, después de estudiar en Roma, decidieron emprender una vida ascética primero en Occidente y después en Oriente, cuna del monasticismo.

23. Marx 1898, 11: Quod haec terra mathematicorum, quorum doctrinam respicere videtur nomen Filastrii, fuit patria, quod Philastrium illum qui nomen suum inscripsit in sepulcris Thebanis ea de causa in illa terra vixisse probabile est.

24. Juret 1904, realizó su tesis doctoral sobre la gramática del latín de Filastrio. Además, propone en bastantes ocasiones diferentes lecturas textuales y reconstrucciones a la edición de Marx.

25. Juret 1904, 5. Así mismo, Bardy, en la entrada de Filastrio en el DThC 12, 13981399, lo considera latino, quizás seguramente influido por la historiografía francesa.

26. De familia pagana, Taciano escribió una obra en la que lanzaba algunos de los mayores ataques contra el paganismo. Por su parte, Atanasio (328-373), a pesar de su cultura griega, de su pensamiento forjado en la cultura helena, refleja en todos sus escritos una fuerte antítesis entre el paganismo y el cristianismo. Uno de sus mayores exponentes es la Oratio contra gentes (ed. y trad. fr. de P. T. Camelot, SC 18 Bis, Paris, 1977). 
es ni griego ni latino: Attamen prout S. Filastrius loquitur de Graecis et Latinis non videtur neque Graecus neque Latinus ${ }^{27}$. Para ello remite a las herejías 111.5 y ss. y 121.7 y ss. En ambos pasajes Filastrio habla de los orígenes de los griegos y romanos en tercera persona. No obstante, esto no supone un argumento definitivo para no considerarlo griego o romano, pues el tono general que confiere a su obra es, en su mayor parte, impersonal. Además, nos encontramos con autores como Clemente, originario de Alejandría, quien al hablar de las prácticas religiosas de otros grupos o pueblos que no sean cristianos, como las de los egipcios, emplea un tono ajeno a sus circunstancias, como si no se encontrara él mismo en Egipto ${ }^{28}$.

Frente a estas opiniones y los datos con los que contamos, se nos presentan dos posibles opciones. La primera, y quizás la más habitual, es que Gaudencio sigue unos topoi literarios establecidos y explotados normalmente por otros autores contemporáneos a la hora de redactar la biografía de un personaje fallecido ${ }^{29}$. En este ejemplo concreto no solamente encontramos el parecido con la cita de Gn 12.1, sino que aparece en un pasaje del Evangelio de Marcos (6.4) en el que Jesús es expulsado de su patria, Nazaret, por realizar prodigios. Jesús se resigna diciendo: Quia non est propheta sine honore nisi in patria sua, et in domo sua, et in cognatione sua: "No hay profeta sin honra sino en su propia tierra, en su propia casa y entre sus parientes ${ }^{30}$. Vemos, de nuevo aquí, la evidente similitud entre ambas afirmaciones. De hecho, lo más probable es que Gaudencio tuviera in mente este pasaje del evangelio de Marcos. Un poco más adelante, en el versículo 6 del capítulo 6 , el evangelista describe la actividad de Jesús por los entornos: circuibat castella in circuitu docens. Esta referencia a la predicación por diferentes aldeas también se la atribuirá Gaudencio a Filastrio más adelante en el texto (Serm. 21.7). Observamos cómo su biógrafo trata de relacionar la actividad de Jesús como predicador ambulante por el territorio judío con la iniciada por Filastrio por "todo el mundo» y, más concretamente, por el mundo itálico. Su discurso desarrolla este aspecto aún más al presentarnos a Filastrio dotado de un gran espíritu emprendedor y aventurero, que lo llevó a recorrer «todo el

27. Portarena 1946, XII.

28. Entre los numerosos ejemplos en su obra, $c f r$. Clem. Alex., Prot. 2.11.24.36.39.

29. Un ejemplo muy parecido lo encontramos en una epístola de Ambrosio al pueblo de Vercelli, Ep. Extra collec. 14.68. Ambrosio asegura que el primer obispo de la ciudad de Vercelli, Eusebio, había optado por abandonar su casa y recorrer diversos lugares siguiendo el ejemplo de Elías, Elisa y Juan (Bautista). Cfr. Liebeschuetz y Hill 2005, 318-319.

30. Se trata de un dicho proverbial presente también en los demás evangelios, aunque el que más relación guarda con el de Marcos es Mt 13.57. Cfr. Lc 4.24; Jn 4.44. 
territorio romano ${ }^{31}$ predicando la palabra de Dios. Lo compara en esta ocasión con el mismo Pablo de Tarso, una de las figuras más importantes del cristianismo, el viajero por excelencia. El emular las actividades de los apóstoles, sobre todo la de Pablo o Pedro, era de gran estima y todo un honor.

La segunda opción es mantener abierta la posibilidad de que Filastrio sea oriundo de Egipto, como aseguraba Marx, o al menos oriental ${ }^{32}$. Esta hipótesis, en efecto, es muy verosímil, pues existen numerosos casos de personajes que, procedentes de la Pars Orientis, se trasladaron a Occidente para difundir el cristianismo, incluso llegando a convertirse en obispos de sedes importantes ${ }^{33}$. Además, sabemos que la movilidad a lo largo del Imperio se había hecho posible incluso para los grupos más humildes de la sociedad, como hemos de suponer en el caso de Filastrio. Así nos lo han mostrado evidencias provenientes del territorio egipcio ${ }^{34}$. Para reforzar esta hipótesis nos podríamos apoyar en las numerosas alusiones que hace sobre el territorio egipcio en su obra. Este, en todo caso, no es un argumento de peso, puesto que en los libros del Antiguo Testamento esta zona resulta de gran relevancia y, además, la exégesis veterotestamentaria tuvo un enorme protagonismo frente a la neotestamentaria. Un detalle que nos ha llamado especialmente la atención se encuentra en la herejía 121.9, donde Filastrio parece citar de memoria, prácticamente igual, un pasaje del Timeo de Platón en el que uno de los personajes de este diálogo, Critias, cuenta las hazañas de Solón, uno de los siete sabios de Grecia, en su visita a Egipto (Tim. 21-22). Critias presenta a Solón debatiendo con unos sacerdotes egipcios para demostrar la antigüedad de su ciudad, Atenas. Para ello les cuenta la historia del primer hombre, Foroneo, y del

31. Gaudent., Serm. 21.6 (CSEL 68, 186): circuiens universum paene ambitum Romani orbis dominicum praedicavit verbum. Sobre las travesías ascéticas y monásticas en este mismo periodo, $c f r$. Dietz 2004.

32. Koch 1938, 2126, propone, igualmente, que hay algunos pasajes de su obra que hacen sospechar que no fue ni romano ni itálico.

33. Entre estos recordamos a Hermas; Clemente de Roma; Ireneo, obispo de Lyon, la ciudad gala más importante, e Hipólito, todos ellos venidos de la pars orientis del Imperio. El cristianismo occidental en sus orígenes se caracteriza por tener una fuerte presencia de inmigrantes "descoordinada» y «desigual» (Humphries 2008, 288-289). Según Gritti 2018, 17 , n. 5, experta en la prosopografía del norte de Italia en el periodo que nos ocupa, el $85 \%$ de los personajes del periodo tardoantiguo tratados en su obra provienen, o al menos supuestamente, de la Pars Orientis.

34. Leyerle 2009, 110-111: "In Egypt, the practice of "cutting loose and taking off" (anachōrēsis) was so common that it became the technical term for religious withdrawal. Recent studies have sharpened our awareness of monastic mobility, identifying travel as a widespread ascetic practice». 
diluvio y la supervivencia de Pirra y Deucalión. Al final de su relato los sacerdotes empiezan a reírse de él por creer que sus historias eran muy antiguas, siendo a su parecer todo lo contrario. Esta es la única ocasión en toda la obra en que Filastrio cita directamente el nombre y el texto de un autor pagano y es, precisamente, un pasaje en el que unos sacerdotes egipcios se muestran superiores a los griegos. ¿Conocía de memoria el obispo este pasaje por representar el "orgueil patriotique» del que hablaba Juret? Este detalle es, cuando menos, llamativo por ser único en su obra. En la casi imposible tarea de identificar las fuentes que utiliza Filastrio para construir su catálogo, hemos encontrado un autor que menciona este mismo pasaje. Se trata de Clemente de Alejandría. En el primer libro de sus Stromata cita en dos ocasiones el pasaje de Platón (I.69.3; I.180.12). Sin embargo, no hemos localizado otros pasajes en el Liber que presenten una equivalencia clara con Clemente de Alejandría, aunque hay numerosos temas, preocupaciones y críticas que coinciden. No obstante, esta cita podría provenir de Clemente de forma indirecta, esto es, a través de otras fuentes como excerpta o doxografías ${ }^{35}$. A lo largo de su obra trata aspectos muy comentados por autores anteriores y contemporáneos suyos, de forma que muchas de sus informaciones podrían provenir de sus lecturas o simplemente a través de los contactos establecidos durante sus andanzas. Ahora bien, lo que debemos subrayar de la cita del Timeo es que esa información resultaba importante para Filastrio. Como hemos mencionado, es un proceder extraño en este autor, pues nunca cita directamente ningún otro escrito, ya sea de autores cristianos o paganos. Por lo tanto, esta cita le resultó lo suficientemente interesante, no sabemos exactamente los motivos, como para recogerla en su obra.

Por todo ello, la noticia de haber dejado su casa no tiene por qué implicar que Filastrio proviniera de otro territorio que no fuera el itálico, sino que sencillamente Gaudencio aprovechó un conocido fragmento de la Escritura, como tan a menudo encontramos entre los autores cristianos, para plasmar las andanzas de Filastrio, pero no necesariamente por «todo el territorio romano» (21.6). Normalmente en este tipo de literatura se tiende a la exageración para otorgar un mayor prestigio y valor al difunto. No obstante, nos inclinamos a creer en la posibilidad de un origen egipcio o, en todo caso, de la parte oriental del Imperio. Entre los argumentos más plausibles se encuentran: (1) en primer lugar y, por tanto, el más destacable, la utilización de un catálogo contra las herejías escrito en griego, conocido como Syntagma, hoy perdido. Este fue compuesto por Hipólito (Euseb. Caes., HE 6.22), un prolífico autor oriental y obispo de alguna

35. Esta es la opinión de Heylen 1957, 604. 
sede episcopal, probablemente en Asia Menor ${ }^{36}$ o la zona de Palestina; (2) después, la etimología de su nombre de origen griego; (3) el hecho de que Gaudencio lo presente como un asceta ${ }^{37}$, una forma de vida proveniente del monaquismo oriental, siendo en Egipto el lugar de origen en la segunda mitad del siglo III (apenas una generación antes del nacimiento de Filastrio) y en donde se dio un profundo desarrollo de este modelo de vida religiosa; (4) las constantes alusiones a Egipto a lo largo de su obra, entre las que resaltamos la explicación en la que compara a una gran piedra del templo de Jerusalén con un obelisco, construcción típica egipcia (Div. her. 21.2); (5) la prescripción de utilizar la versión bíblica de los Setenta como la única válida y el detallado relato de cómo fue realizada (Div. her. 142); (6) la cita del pasaje del Timeo de Platón (Div. her. 121.9); (7) y los buenos conocimientos geográficos que demuestra, especialmente de la Pars Orientis del Imperio ${ }^{38}$. Todos los argumentos aquí presentados, aunque se muestran frágiles, nos aportan unos indicios que pueden perfectamente concordar con las palabras de Gaudencio.

\section{MOVILIDAD y LUCHAS DE PODER ECLESIÁSTICO}

De su origo y primeros años de vida adulta Gaudencio continúa su narración presentando los rasgos típicos de todo aquel que se dedicara a

36. Cfr. Simonetti 2000, 130-131.

37. Aunque puede tratarse de un topos literario, según las fuentes literarias, gran parte de los obispos del siglo IV, especialmente en el Oriente, habían comenzado su vida religiosa como ascetas.

38. Filastr., Div. her. 121.3-4 (CCSL 9, 285): Cham etiam secundo filio omnes Syrias et diocesin Aegypti, Africae, Aethiopiae ingentem latitudinem prope fines tendentem oceani atque Hispaniarum censendo distribuit, possidendamque eam atque babitandam spiritu diuino praenuntiauit, in medio autem usque ad Cappadociam, id est Tauri montem, fines habere concessit. Tertio autem, Iapheth nomine, Cappadociam ingredientibus atque a Cilicia exeuntibus loca frigida, quae sunt Armeniae, Bosfori, Ponti, Thraciae, Pannoniarum, Illyrici, Italiae, et occidentis uniuersas partes iussu diuino ei statuendo adtribuit; "A Kham, el segundo hijo, le dejó todas las Sirias y las diócesis de Egipto, África y Etiopía, una grandísima extensión hasta los límites con el océano, incluyendo las Hispanias. Y predijo que ese territorio debía ser poseído y habitado por un espíritu divino, además le concedió el poseer los extremos, desde el centro de la tierra hasta Capadocia, exactamente hasta el monte Taurus. Para el tercero, que tenía por nombre Iáfeth, le asignó por orden divina para los que entrasen en Capadocia saliendo de Cilicia unos emplazamientos gélidos, que son los de Armenia, el Bósforo, el Ponto, Tracia, las Panonias, el Ilírico, Italia y toda la zona de occidente mediante su decisión". Los detalles que aquí presenta sobre la geografía oriental de Asia Menor no son comunes en su obra. Los pasos de montaña del Taurus eran bastante difíciles de cruzar. Sobre este territorio en época tardoantigua, $c f r$. Elton 2004. 
la vida religiosa cristiana, esto es, la práctica de una ascesis extrema (continentiam singularem) y el aprendizaje continuo de las Escrituras (pervigil in scripturis sanctis dei sapientiam concupivit) (21.5). Estas palabras nos llevan a imaginarnos a este personaje llevando una especie de vida monástica durante un periodo de tiempo, tras marcharse de su casa ${ }^{39}$. Al final de este aprendizaje consiguió el rango de dispensator tras la imposición de manos de los presbíteros. No sabemos dónde pudo ocurrir esta especie de ascenso o de prueba superada después de una formación en las enseñanzas cristianas. Tampoco sabemos qué opciones se le presentaban una vez conseguido este estatus. Este término, procedente del mundo administrativo romano ${ }^{40}$, según Cipriano de Cartago (mediados s. III), equivale a sacerdote ${ }^{41}$. Por lo que podemos suponer que, a partir de ese momento, podía instruir a otras personas o, al menos, estaba en condiciones de predicar la doctrina cristiana como, efectivamente, hizo.

Según su biógrafo, además de ir predicando y enseñando por diversos lugares, Filastrio combatió ante paganos, judíos y herejes (21.6). Esta afirmación ha contribuido a especular sobre otras posibles obras de Filastrio contra paganos y judíos ${ }^{42}$. Aunque posible, no creemos que fuera cierto, en primer lugar, porque por el contexto se entiende que el verbo "luchar" (pugnavit) alude al enfrentamiento físico y, por supuesto, dialéctico contra miembros de estos dos colectivos, enemigos de los cristianos prácticamente desde sus orígenes. De hecho, Gaudencio continúa la oración explicando que de entre hereses omnes, especialmente se enfrentó a la furentem eo tempore Arrianam perfidiam. Si damos crédito a estas palabras, las discusiones acabaron siendo tan violentas que Filastrio resultó duramente azotado y golpeado: verberibus subderetur et in corpore suo stigmata domini nostri Iesu Christi portaret (21.6). Una vez más, estas afirmaciones nos remiten directamente a las pronunciadas por Pablo. En su

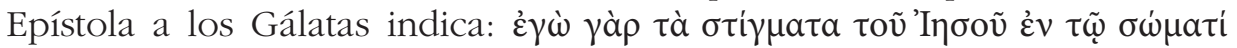

39. Hubo grupos de ascetas en el occidente desde el siglo II, pero no es hasta la década de 340 cuando Eusebio, obispo de Vercelli, ciudad en el norte de Italia, tras su vuelta del exilio en Oriente, obliga a su clero a llevar una vida monástica (Dunn 2007, 669).

40. El dispensator era un esclavo encargado de pagar al servicio de una domus u otra clase de pagos. No obstante, sus funciones varían según el emplazamiento (zona rural o urbana) y la jerarquía social de su dueño. Cfr. s. $v$. "dispensator», en Daremberg y Saglio 1969 , t. 2, 280-286.

41. Cypr., Ep. 59.5: sacerdotes id est dispensatores eius (Christi). Cfr. s. v. «dispensator", Blaise 1954, 281.

42. Lizzi 1989, 127, n. 126: "Dalla frase di Gaudenzio si è avvanzata l'ipotesi che Filastrio potesse aver scritto oltre al trattato contro gli eretici anche un'opera antigiudaica». 
$\mu$ ov $\beta a \sigma \tau \dot{\alpha} \zeta \omega^{43}$. Se vuelve a comparar a Filastrio con Pablo. Ambos tenían grabadas las marcas o, más bien, las heridas recibidas durante su predicación. Estas señas parecen indicar un motivo de orgullo entre los defensores del cristianismo - no todos ciertamente- y al mismo tiempo se equiparan con los tradicionales estigmas, sellos que se imprimían a fuego en los cuerpos de los esclavos ${ }^{44}$. De nuevo, llama la atención esta expresión, pues no es común que se ensalce el hecho de que el obispo de una ciudad relativamente destacada haya sido apaleado y, como consecuencia de ello, sus cicatrices sirvan de ejemplo y de orgullo para la comunidad cristiana. A este respecto se debe añadir que la ciudad de Brescia, y, por ende, sus obispos, había mantenido una estrecha relación con la de Milán, simbolizada en el obispo aristócrata por excelencia: Ambrosio. Este último con toda probabilidad no estaría de acuerdo con este tipo de prácticas violentas. No obstante, estos enfrentamientos, normalmente entre cristianos y paganos o judíos, pero también entre los propios cristianos, fueron frecuentes y debieron provocar sangrientas escenas ${ }^{45}$. Siendo tal su naturaleza que el poder imperial decidió poner límite a estos disturbios bajo pena mediante una ley promulgada por los emperadores Valentiniano, Teodosio y Arcadio al norte de Macedonia en junio del año $388^{46}$. Normalmente se sitúa en el origen de estos altercados el conflicto arriano. Se

43. Gál 6.17: «Pues yo llevo las marcas ( $\sigma \tau i \gamma \mu \alpha \tau \alpha)$ de Jesús en mi cuerpo». Estas palabras de Pablo parecen ser recordadas en la carta sinodal del concilio de Constantinopla enviada a Roma en el 382: Alii diversis macerati suppliciis adhuc stigmata Christi et vulnera in suo corpore circumferre noscuntur (Ritter 2006, 59). Sobre este mismo tema habló ante el pueblo de Milán en el 386 Ambrosio en un discurso contra la polémica arriana; C. Aux. PL 16, 1009: Tentator ille diabolus per ministros suos certamen auget, vulneribus corporis mei experiendum arbitratur. Scio, fratres, vulnera haec, quae pro Christo excipiamus non esse vulnera, quibus vita non amittitur, sed propagatur.

44. Esta práctica también ocurría con los esclavos dependientes de templos en suelo egipcio. Cfr. Hdt., 2.113 (BCG 3, 400, n. 409). Sobre el uso de stigma en el cristianismo primitivo, cfr. Setién 2020.

45. Hay toda una literatura sobre los debates, la mayoría de las veces seguramente ficticios, entre estos grupos. Citamos entre los estudios modernos sobre el tema los de Torres 2016 y 2018.

46. CTh 16.4.2: Nulli egresso ad publicum vel disceptandi de religione vel tractandi vel consilii aliquid deferendi patescat occasio. Et si quis posthac ausu gravi adque damnabili contra huiusmodi legem veniendum esse crediderit vel insistere motu pestiferae perseverationis audebit, competenti poena et digno supplicio coherceatur; "Que no se dé ninguna situación en la que alguien salga a la calle para discutir sobre religión o tratar o anunciar opinión alguna. Y si a alguien después de esto le pareciera que debiera actuar contra una ley semejante llevado por un atrevimiento resuelto y reprochable o se atreva, movido por una obstinación funesta, a proseguir, que sea reprimido por una pena en correspondencia y un castigo merecido» (trad. propia a partir de la edición de Mommsen en SCanon 2, 184-186). 
aprovechó repetidamente la utilización de este nombre para atacar a los enemigos religiosos. De ahí que la herejía arriana que menciona Gaudencio como rival de Filastrio no es otra que el grupo de cristianos "homoianos" (homoios), liderados por Auxencio, obispo de Milán desde el año $355^{47}$. En esta ciudad Filastrio debió de colaborar, quizás ocupando un puesto elevado o siendo incluso el líder, en el fortalecimiento del partido católico frente al liderado por Auxencio. ${ }^{48}$ Así lo indica Gaudencio: Nam et in Mediolanensi urbe idoneus olim custos dominici gregis fuit Arriano repugnans Auxentio, priusquam beatus eligeretur Ambrosius (21.7).

Después de Milán (o quizás antes) Filastrio pasó una larga estancia en Roma, donde llevó a cabo una prolífera labor de proselitismo, ganándose a muchos adeptos gracias a una poderosa oratoria ${ }^{49}$. ¿Se uniría a la comunidad cristiana de la vieja capital? Seguramente entraría en contacto con otros líderes nicenos ${ }^{50}$. Antes de establecerse definitivamente en Brescia, recorrió diferentes emplazamientos llevando el cristianismo al mundo rural ${ }^{51}$. ¿Fue este un periplo sin compañía? Sabemos que el obispo de Roma envió delegaciones a visitar la capital imperial en torno a la

47. Auxencio de Milán, originario de Capadocia, primero fue sacerdote de la iglesia arriana de Alejandría (339-354) y después se convirtió en obispo de Milán con el apoyo del emperador Constancio. Tras el concilio de Rímini del año 359 los obispos nicenos lo declararon arriano y, por tanto, fue condenado como hereje. Sin embargo, a pesar de esta condena y de otras sucesivas, seguiría ocupando el cargo de obispo de la ciudad de Milán hasta el momento de su muerte en el 374. Cfr. s. v. "Auxentius 1", en Pietri y Pietri 1999, 238241; "Auxentius (I)», en Gritti 2018, 130-196. Bardy et al. 1950, 279, proponen que Auxencio se marchó de Milán en el 373.

48. Según Treccani 1963, 349, Filastrio fue elegido guía del partido católico de Milán entre los años 368-72. Por su parte, en el 365 Hilario de Poitiers y Eusebio de Vercelli reunieron un pequeño concilio en Milán con el objetivo de despojar a Auxencio de su cargo tras acusarlo de arriano. La comisión encargada de esclarecer el caso absolvió a Auxencio de estas críticas. Posteriormente, este siguió siendo apoyado por el emperador Valentiniano (Simonetti 1975, 381-83).

49. Gaudent., Serm. 21.7 (CSEL 68, 186): publica et privata disputatione lucratus in fide est.

50. Se han resaltado notables similitudes entre este y un autor contemporáneo suyo situado en Roma en estos mismos años y apodado convencionalmente como Ambrosiaster. Cfr. Wittig 1909.

51. Lizzi 2001, 65: «These country people were the object of the missionary efforts of those bishops». Entre estos se encuentran conocidos obispos como es el caso de Fortunaciano, obispo de Aquilea entre 342-ca. 368. Lizzi realiza un profundo y detallado estudio sobre el proceso de expansión del cristianismo en el norte de Italia que ocupó el espacio de siglo y medio. A partir de las evidencias que han llegado hasta nuestros días, según esta investigadora, desde mediados del siglo III comienzan a aparecer las primeras comunidades cristianas en las ciudades más importantes y para comienzos del siglo V se da por completa la plena cristianización de la comunidad cívica en la zona (p. 49). 
década del $350^{52}$. Desde Constantino era frecuente que los emperadores participaran de los asuntos religiosos y, ahora que la capital era Milán, la Italia Annonaria era una zona muy atrayente para quienes deseaban procurarse un asequible "cursus episcopalis". Por ello, resulta del todo posible imaginarnos a este personaje emprendiendo camino desde la antigua capital hacia el Norte, hacia un territorio fértil para el cristianismo en plena expansión gracias al apoyo imperial ${ }^{53}$.

\section{El EPISCOPADO}

En la última parte de la biografía Gaudencio cuenta cómo Filastrio acabó instalándose en Brescia y desempeñando el cargo de obispo de la ciudad. No sabemos en qué circunstancias ni el momento exacto en que su elección pudo suceder o incluso si hubo un nombramiento, pues, de haber sido así, seguramente lo hubiera expresado. Es muy posible que no llegara a ser obispo de Brescia mientras Auxencio se encontraba a la cabeza de la comunidad cristiana de Milán, ya que las demás ciudades de la Italia Annonaria dependían del consentimiento del obispo de la capital. No es muy lógico, por tanto, que un rebelde católico fuera nombrado obispo de una ciudad importante tan cercana a Milán bajo el mando de un arriano. En esta, según el testimonio de Gaudencio, «no se conocía aún la nueva religión", aunque estaba "deseosa por aprender" (cupida doctrinae promeruit, scientiae quidem spiritalis ignara, studio tamen discendi laudabilis) (21.8).

Resulta bastante atractiva la retórica que emplea Gaudencio a continuación para explicar metafóricamente la labor del obispo mediante las distintas tareas que debe realizar el bonus agricola. Este construye unas habilidosas comparaciones para su público ${ }^{54}$ : como un campesino, Filastrio "cortó sin tardar desde lo más profundo de sus raíces un bosque terrible de numerosos errores", su arado no era otro que el de la propia "doctrina» y sus semillas eran "los mandamientos de la vida». Y continúa describiendo la labor de este mediante plásticas metáforas como las que acabamos de señalar. Esta alegoría hace de Filastrio el promotor y único

52. Humphries 1999, 94 .

53. Este mismo recorrido parece haber realizado el africano Fortunaciano hacia el 330. Desde su tierra natal emigró a Roma donde estuvo un tiempo y de ahí subió hacia el norte de Italia hasta convertirse en el obispo de la próspera ciudad de Aquilea. $C f r$. Sotinel 2005, 116.

54. Es un rasgo característico del estilo de Gaudencio, véase, por ejemplo, Serm. 16.9. 
encargado en evangelizar a la población brixiense. Es más, en el Sermo 16.8 asegura que fue él mismo quien fundó la Iglesia en la ciudad:

[...] maxime post illam venerandae memoriae patris mei Filastrii eruditissimam vocem, quae per gratiam Spiritus sancti large effluens, banc ecclesiam in fide Trinitatis adorandae fundavit, in vera spe, et caritate perfecta constituit, ad virtutes erexit, in pace reliquit.

[...] Sobre todo a partir de la doctísima palabra de mi padre Filastrio, de venerable recuerdo, fluyendo esta ampliamente por gracia del Espíritu santo, fundó esta iglesia en la fe de la venerable Trinidad, la constituyó con verdadera esperanza e impoluta caridad, la erigió hacia la virtud, la dejó habiendo alcanzado la paz ${ }^{55}$.

Sabemos que esto no es del todo cierto. Parece ser que la iglesia de esta ciudad fue fundada en el primer tercio del siglo IV por Clateo, discípulo del obispo milanés Anatalón. Esta sería la primera iglesia independiente de Milán. Aún con más seguridad se puede hablar de los siguientes obispos, como es el caso de Ursicinus, sexto obispo de Brescia, cuyo nombre aparece en la lista de participantes del concilio de Sérdica en el $343^{56}$. No hay duda de su tradición nicena. Un ejemplo de ello es la aparición de esta ciudad en el conflicto donatista. En el 312 fue elegido obispo de Cartago el católico Caecilianus ${ }^{57}$. Desde el comienzo en el cargo se vio enfrentado, por un lado, contra otros aspirantes al puesto y, por otro, contra Donato. En algún momento entre el 314-316 se encuentra "retenido", según Optato de Milevi, en la ciudad de Brescia mientras que dos obispos itálicos acuden a Cartago para elegir a un obispo que sea aceptado por los dos grupos (donatista y católico). De este incidente se ha conjeturado la presencia de una comunidad cristiana en esta ciudad ya en la década del $310^{58}$. En efecto, poco tiempo después (antes de finales del 316) Ceciliano se sometió a examen ante el propio Constantino en Milán. Vemos, por tanto, el estrecho vínculo entre Brescia y Milán al comienzo del siglo IV.

Por otro lado, podemos entender la oración hanc ecclesiam in fide Trinitatis adorandae fundavit en el sentido de que, antes de ser elegido

55. Gaudent., Serm. 16.8 (CSEL 68, 139) (trad. propia).

56. Zani 1992, 149. Solamente participaron en este concilio cinco obispos del norte de Italia: de Aquilea, Milán, Rávena, Verona y Brescia. Según Cracco Ruggini 1988, 75, Latinus, tercer obispo de Brescia, habría recibido una formación eclesiástica antes de ser elegido obispo. Para ello se basa en una inscripción a la que Picard no ofrece plena veracidad (CIL V, $4846=$ ILCV 1038, Picard 1988, 222, n. 87).

57. Cfr. s. v. "Caecilianus 1", Mandouze et al. 1982, 165-175.

58. Humphries 1999, 82 . 
Filastrio obispo, la iglesia de Brescia no seguía el credo niceno de la Trinidad, sino que era arriana. Esta opción es totalmente válida si tenemos en cuenta que el obispo de Milán, el arriano Auxencio, tenía potestad sobre los nombramientos de las otras iglesias de su diócesis. Esta situación explicaría las circunstancias oscuras en las que fue elegido obispo Filastrio y el silencio absoluto de Gaudencio sobre el predecesor de este.

En todo caso, también debemos entender que las palabras de Gaudencio sobre la labor realizada por Filastrio tengan relación con la población pagana de la zona. La mención de "un bosque» plagado de "errores» bien podría aludir a las prácticas tradicionales como la idolatría o los sacrificios propios de la religión romana ${ }^{59}$.

Para finalizar, la última sección de esta parte (21.11-14) está dedicada a describir el carácter del obispo. Destaca principalmente en este apartado su estilo casi poético, a base de numerosos recursos retóricos, uso constante de adjetivos calificativos, construcciones yuxtapuestas y todo un campo semántico que invita a la alabanza y la admiración. En cuanto a la forma, nos evoca directamente a los retratos de autores clásicos - e. g. el famoso de Catilina (Sal., Cat. 5)—. Gaudencio dibuja la persona de Filastrio completamente idealizada. Entre sus cualidades destacan: un pródigo conocimiento de las Escrituras, indispensable para cualquier cristiano culto, su humildad y su desapego de todo lo material en consonancia con la práctica ascética que mencionaba al comienzo del discurso: "Cuan grande fue su conocimiento así también fue su distinguida humildad, cuan grande fue su pericia en los asuntos celestes así también su desconocimiento de los terrenales ${ }^{60}$. Por otro lado, resultan contradictorias las afirmaciones de que, supuestamente, rehuyera de las relaciones personales y al mismo tiempo hiciera de administrador participando en los asuntos económicos de la ciudad: «Él ayudaba a los más pobres comerciantes comprando pródiga y desinteresadamente los productos de cada día ${ }^{61}$. Filastrio parece haber sido un obispo en estrecha relación con su pueblo; inter humana colloquia ingiter occupatus (21.11); «accesible a las personas sin importar la edad, condición o sexo mostrando una extraordinaria bendición, de hecho, estaba más unido a los más humildes» (21.12).

Pero también se presenta la cara del obispo que se comporta como un monje renunciando al mundo, practicando una dura ascesis, sin querer relacionarse con otras personas, ni tener ningún tipo de aspiración

59. En otras partes de sus Sermones Gaudencio arremete contra las prácticas idolátricas.

60. Gaudent., Serm. 21.11 (CSEL 68, 188), trad. propia.

61. La ciudad Brescia parece haber destacado por la producción y comercio de lana, Humphries 1999, 30. 
material y su forma de vestir, sencilla como ninguno, directamente vinculada con un carácter puro y humilde. A pesar de ello, se preocupa por su población, por su economía, especialmente la de los más humildes ${ }^{62}$. Se hace patente una clara antítesis entre el ideal del monje y el del «civic patronus as benefactor and protector, administrator and politician ${ }^{63}$. Se muestran, por tanto, aquí las variadas facetas que un obispo de su tiempo debía poseer. Se hace gala de ese perfil poliédrico de la figura episcopal que ha sido tan tratado en las últimas décadas por la investigación. Sus cualidades morales y psicológicas serán una constante en las biografías cristianas de este periodo.

Hilario de Arles (ca. 430) presentaba a su predecesor, Honorato, mostrando anhelo por la pobreza y por las labores manuales ${ }^{64}$. De hecho, ambas biografías presentan estrechas similitudes: comparten las características propias del discurso encomiástico o panegírico, cuyo objetivo último es ensalzar las virtudes de los difuntos, además de ser concebidos para emitirse oralmente ante el pueblo.

Para terminar su sermo, haciendo uso de una característica modestia ${ }^{65}$, advierte de la brevedad del panegírico brindado a su patrono (21.14). El hecho de considerarlo como su patrono y de haber celebrado durante 14 años «su culto" nos lleva a pensar que el episcopado de Filastrio debió ser dilatado. El recuerdo siempre presente de los que le siguieron da muestra de que solamente tras años de dedicación logró una comunidad cristiana mucho más definida, sin que ello supusiera una completa cristianización de la zona ${ }^{66}$.

\section{Conclusiones}

En definitiva, el breve panegírico compuesto por Gaudencio nos ofrece un cuadro bastante amplio de cómo pudo haber sido la vida y la persona de Filastrio. Todos los aspectos recogidos por él son típicos de

62. Estas cualidades prácticas, quizás más a menudo de lo que creemos, primaban sobre los aspectos puramente teóricos. El caso de Cipriano de Cartago es bastante revelador. Recientes investigaciones sugieren que fue elegido obispo (248/249) por la mayoría de la población, pero no por la mayoría del clero de la ciudad. De hecho, acababa de convertirse al cristianismo apenas dos años antes, $c f r$. Heine 2004, 156.

63. Humphries 1999, 35.

64. Deferrari 2001, 355-394.

65. En el sermón ofrecido el día de su consagración repite constantemente que no está a la altura de semejante tarea. Cfr. Lizzi 1989, 97-106.

66. Aunque así se haya creído durante mucho tiempo, para finales del s. IV el cristianismo no había alcanzado a la gran mayoría de la población. Cfr. Lizzi 1990, 161. 
cada una de las biografías de este periodo, incluso de las de los propios emperadores, siendo su máximo exponente la figura de Constantino ${ }^{67}$. La presentación de un ideal de vida cristiana tiene por fin último impulsar a sus oyentes o lectores a seguir ese modelo. Llegados a este punto, hacemos nuestras las palabras de Averil Cameron (2000, 83): "These Lifes are not innocent histories; they are didactic and apologetic works». En relación con esto, se presentan las características más representativas de las funciones episcopales, aunque en algunos aspectos nada propias de un obispo, como sus episodios más violentos. Además, el relato refleja las motivaciones y preocupaciones históricas del propio biógrafo. Podemos suponer que una de sus motivaciones más fuertes era la de recordar al pueblo la importancia del obispo para la buena convivencia, la prosperidad y, en definitiva, la salud de sus feligreses. En estos años, en los que iban apareciendo grupos de invasores por sus territorios, era pertinente promover el papel sociopolítico y económico que este ordo representaba.

En cuanto a la historicidad del texto analizado, al compararlo con la propia obra de Filastrio y otros datos del contexto histórico del siglo IV, hemos podido argumentar un posible origen oriental, así como su posterior traslado de adulto al norte de Italia, pasando por Roma. Una vez instalado en este territorio, Filastrio desempeñó muy probablemente un papel destacado dentro de la comunidad nicena de la capital imperial, enfrentándose al empoderado bando arriano liderado por Auxencio. Seguramente a partir de este protagonismo acabó siendo el obispo de Brescia, segunda ciudad cristiana de la zona tras Milán. En esta llevó a cabo las funciones más prácticas y cotidianas de una pequeña comunidad cristiana al mismo tiempo que dedicó, muy seguramente, un notable esfuerzo a la tarea intelectual de leer obras cristianas y de la escritura de la suya propia.

\section{Fuentes}

Banterle, Gabriele, trad. it. San Filastrio di Brescia, Delle varie eresie. Milano-Roma, 1991.

Deferrari, Roy J., trad. ing. Early Christian biographies: lives of St. Cyprian, by Pontius; St. Ambrose, by Paulinus; St. Augustine, by Possidius; St. Anthony, by St. Athanasius; St. Paul the first hermit, St. Hilarion, and Malchus, by St. Jerome; St. Epiphanius, by Ennodius. Washington, 2001. Glueck, Ambrosius, ed. S. Gaudentii Episcopi Brixiensis Tractatus (CSEL 68). Vindobonae-Leipzig, 1936.

67. Cameron 2000, 78. 
Heylen, Frederich, ed. Filastri Episcopi Brixiensis, Diuersarum hereseôn liber (CCSL 9). Turnholti, 1957.

Le Code Théodosien. Livre XVI, et sa réception au Moyen Âge. Texte latin de l'édition Mommsen et traduction française. Introduction, trad. et notes par Élisabeth Magnou-Nortier (Sources Canoniques 2). Paris, $2002=$ SCanon 2.

Marx, Friedrich, ed. S. Filastrii Diversarum Hereseon Liber (CSEL 38). Vindobonae, 1898.

Ramos-Lisón, Domingo, ed. y trad. esp. Gaudencio de Brescia, Sermones (FuP 105). Madrid, 2017.

Ritter, Adolf Martin. «Concilium constantinopolitanum I, 381». En Conciliorum oecomenicorum generaliumque decreta I, Corpus Christianorum, editado por Adolf Martin Ritter, 36-70. Turnhout, 2006. Simonetti, Manlio. Ippolito, Contro Noeto. Bologna, 2000.

Truzzi, Carlo, trad. it. Gaudenzio di Brescia, I Sermoni. Roma, 1996.

\section{Bibliografía}

Bardy, G., Jean-Rémy Palanque y Pierre de Labriolle. De la paix Constantinienne à la mort de Thèodose, vol. 3. Paris, 1950.

Blaise, Albert. Dictionnaire Latin-Français des Auteurs Chrétiens. Turnhout, 1954.

Cameron, Averil. "Form and Meaning. The Vita Constantini and the Vita Antonii. En Greek biography and panegyric in late antiquity, editado por Tomas Hägg, Philip Rousseau y Christian Høgel, 72-88. BerkeleyLos Angeles-London, 2000.

Cox Miller, Patricia. Biography in Late Antiquity: A quest for the boly man. Berkeley-Los Angeles-London, 1983.

Cracco Ruggini, Lellia. "Gli Anicii a Roma e in provincia». Mélanges de l'École française de Rome. Moyen-Âge, Temps modernes 100 (1988): 69-85.

Daremberg, Charles y Edmond Saglio, dirs. Dictionnaire des Antiquités grecques et romaines. Graz. $=$ DAGR, 1969 .

Dietz, Maribel. «Itinerant spirituality and the late antique origins of Christian pilgrimage». En Travel, Communication and Geography in Late Antiquity: Sacred and profane, editado por Linda Ellis y Frank L. Kidner, 125-134. Hants, 2004.

Dunn, Marilyn. "Asceticism and monasticism, II: Western". En The Cambridge History of Christianity. Vol. II. Constantine to c. 600, 
editado por Augustine Casiday y Frederick W. Norris, 669-690. Cambridge, 2007.

Elton, Hugh. "Cilicia, Geography, and the Late Roman Empire». En Travel, Communication and Geography in Late Antiquity: Sacred and Profane,editado por Linda Ellis y Frank L. Kidner, 5-11. Hants, 2004.

Gritti, Elena. Prosopografia romana fra le due partes imperii (98-604). Contributo alla storia dei rapporti fra Transpadana e Oriens. Tomo I (Abundius - G. Kaninius Sissius). Bari, 2018.

Gritti, Elena. Proposografia romana fra due Partes Imperii (98-604). Contributo alla storia dei rapporti fra Transpadana e Oriens. Tomo II (Maraotes - Caius Valerius Surus). Bari, 2019.

Hägg, Tomas, Philip Rousseau y Christian Høgel, eds. Greek biography and panegyric in late antiquity (The transformation of the Classical heritage 31). Berkeley-Los Angeles-London, 2000.

Harland, Philip A., ed. Travel and religion in antiquity. Waterloo, Ontario, CA, 2011.

Heine, R. E. "Cyprian and Novatian". En The Cambridge History of Early Christian Literature, editado por Augustine Casiday y Frederick W. Norris, 152-160. Cambridge, 2004.

Humphries, Mark. Communities of the blessed: Social environment and religious change in Northern Italy, AD 200-400. Oxford, 1999.

Juret, P. C. "Étude grammaticale sur le latin de S. Filastrius». Romanische Forschungen 19 (1906): 130-320.

Koch, Hugo. "Philastrius». En Paulys Real-Encyclopädie der classischen Altertumswissenschaft, 2125-2131. J. B. Metzlersche Verlagsbuchhandlung, 1938.

Leyerle, Blake. "Mobility and the Traces of Empire». En A companion to Late Antiquity, editado por Philip Rousseau y Jutta Raithel (with the assistance of), 110-124. Chichester, 2009.

Lizzi Testa, Rita. Vescovi e strutture ecclesiastiche nella città tardoantica (L'Italia Annonaria nel IV-V secolo d.C.). Como, 1989.

Lizzi Testa, Rita. "Ambrose's contemporaries and the Christianization of Northern Italy». The Journal of Roman Studies 80 (1990): 156-173.

Lizzi Testa, Rita. "Christianization and conversion in Northern Italy». En The origins of Christendom in the West, editado por Alan Kreider, 47-97. Edinburgh-New York, 2001.

Mandouze, André. Prosopographie de l'Afrique chrétienne (303-533), d'après la documentation élaborée par Anne-Marie la Bonnardière avec la collaboration de Claude-Hélène Lacroix, Serge Lancel, Henri Irénée Marrou, Charles Munier, Elisabeth Paoli-Lafaye, Stan-Michel Pelli (Prosopographie chrétienne du Bas-Empire 1). Paris, 1982. 
Marcos, Mar. "El monacato cristiano». En Historia del Cristianismo. I. El mundo Antiguo, editado por Manuel Sotomayor y José Fernández Ubiña, 639-685. Madrid, 2003.

Marcos, Mar. "El obispo y sus biógrafos». En El obispo en la Antigüedad Tardía. Homenaje a Ramón Teja, editado por Silvia Acerbi, Mar Marcos y Juana Torres, 201-216. Madrid, 2016.

Picard, Jean-Charles. Le souvenir des évêques : sépultures, listes épiscopales et culte des évêques en Italie du Nord des origines au Xe siècle. Rome, 1988.

Pietri, Charles y Luce Pietri, eds. Prosopographie de l'Italie chrétienne (313-604): Vol. 2. (Prosopographie chrétienne du Bas-Empire / [fondée par Henri Irénée Marrou et Jean-Rémy Palanque]). Rome, 1999.

Portarena, Dionysius. Doctrina scripturistica S. Filastrii Brixiensis episcopi et textus biblicus ab eo adbibitus. Romae, 1946.

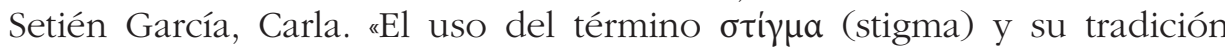
latina en la literatura cristiana primitiva». Revista de Estudios Latinos 20 (2020): 71-90.

Simonetti, Manlio. La crisi ariana nel IV secolo. Roma, 1975.

Torres, Juana. "Conflictos religiosos en el cristianismo antiguo. Los debates entre ortodoxos y herejes». Laicidad y Libertades 15 (2016): 289-310.

Torres, Juana. «Las disputas contra paganos en la Antigüedad tardía: entre el diálogos y la disputatio». Studia Philologica Valentina 20 (2018): 217-242.

Wittig, Joseph. "Filastrius, Gaudentius und Ambrosiaster». En Kirchengeschichtliche Abhandlungen, editado por Max Sdralek, 3-56. Breslau, 1909.

Zani, Antonio. "Filastrio e Gaudenzio vescovi di Brescia tra la seconda metà del IV e la prima decade del V secolo». En Storia religiosa della Lombardia, Diocesi di Brescia, editado por A. Caprioli, A. Rimoldi y L. Vaccaro, 149-167. Brescia, 1992. 